\title{
An Experimental Study on Thermal Conductivity of Ceramsite Cellular Concrete
}

\author{
Q.X. Wang*, Y.X. Shi*, J.B. Shi, Y.G. Zhang, W. Liu \\ Technical Center, \\ China State Construction Engineering Co., Ltd \\ Beijing, China \\ wqxamss@126.com,yunxing_shi@sina.com
}

\begin{abstract}
In this paper, a new type of foam concrete (FC) incorporating ceramsite as a lightweight coarse aggregate was prepared, i.e. ceramsite cellular concrete (CCC). An experimental research was conducted on its thermal properties to clarify the correlation between thermal conductivity and density, compressive strength, thermal storage coefficient and to discuss the influence of ceramsite volume proportion on CCC. Results showed that predictable polynomial models between thermal conductivity and density, compressive strength, and a good linear dependence of thermal storage coefficient on the thermal conductivity can be attained. In addition, it was corroborated that, for the CCC with the design density of $600 \mathrm{~kg} / \mathrm{m} 3$, the appropriate volume proportion of ceramsite was $45 \%$ to present the better influence on thermal conductivity and compressive strength.
\end{abstract}

Keywords-ceramsite cellular concrete; thermal conductivity; ceramsite volume proportion

\section{INTRODUCTION}

Foam concrete (FC) is either a cement paste or mortar with a homogeneous void or pore structure created by entraining air in the form of small bubbles. The introduction of the pore is achieved by the preformed foaming process (foam agent aerated with foaming equipment to form foam before being added to the matrix). Since FC was first patented in 1923 [1], its construction applications as a lightweight non-and semistructural material have been got a rapid promotion, and meanwhile, some comprehensive reviews on FC have been presented $[2,3]$.

However, there are few reports on the ceramsite cellular concrete (CCC) to date, especially on the thermal properties. As a broader category of FC, it has advantages of light weight and higher strength, better thermal insulation, and lower water absorption. In addition, the issue of the thermal insulation of buildings has recently received substantial attention due to the energy crisis [4]. Clearly, there is a need to investigate the thermal insulation of CCC.

In this study, the preformed foaming process was used to prepare the specimens, and these specimens were tested to investigate the correlation between thermal conductivity and density, compressive strength, thermal storage coefficient and to discuss the influence of ceramsite volume proportion on CCC.

\section{EXPERIMENTAL DETAILS}

\section{A. Constituent Materials}

\section{1) Cement}

Composite Portland cement of grade 32.5 was used as the primary cementitious material. The 28-day flexural strength and compressive strengths were 6.6 $\mathrm{MPa}$ and $39.5 \mathrm{MPa}$, respectively, according to the China's national standard GB/T 17671-1999 (Test method of cement strength determination).

\section{2) Mineral Admixture}

Class-II FA was used as the replacement of partial cement. Its apparent density is $2200 \mathrm{~kg} / \mathrm{m}^{3}$, and the bulk density is 925 $\mathrm{kg} / \mathrm{m}^{3}$. The addition of FA was to save cost and reduce the heat of hydration while contributing towards long term strength, Furthermore, it helped to achieve more uniform distribution of air voids.

\section{3) Coarse Aggregate}

The coarse aggregate used in this study was clay ceramsite, which was produced in Beijing city. Its physical properties and outlook are shown in Table I and Fig. 1, respectively.

TABLE I. PhysicAl Properties of CERAMSITE.

\begin{tabular}{|c|c|c|c|c|c|}
\hline $\begin{array}{c}\text { Apparen } \\
\text { t density } \\
\left(\mathbf{k g} / \mathbf{m}^{3}\right)\end{array}$ & $\begin{array}{c}\text { Bulk } \\
\text { density } \\
\left(\mathbf{k g} / \mathbf{m}^{3}\right)\end{array}$ & $\begin{array}{c}\text { Void } \\
\text { content } \\
\mathbf{( \% )}\end{array}$ & $\begin{array}{c}\text { Porosity } \\
\mathbf{( \% )}\end{array}$ & $\begin{array}{c}\text { Water } \\
\text { absorption } \\
\mathbf{( 2 4 h )}(\%)\end{array}$ & $\begin{array}{c}\text { Coefficie } \\
\text { nt of } \\
\text { softness } \\
\mathbf{( \% )}\end{array}$ \\
\hline 500 & 300 & 40 & 74 & 24 & 77 \\
\hline
\end{tabular}

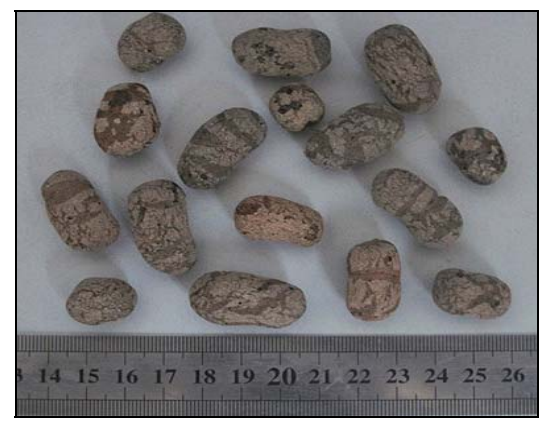

Fig. 1. Outlook of ceramsite. 


\section{4) Superplasticizer}

Liquid polycarboxylate superplasticizer was used in this experiment. Its solid content was approximately $40 \%$, and water reducing ratio was more than $35 \%$.

\section{5) Water}

Water used in this study was potable water.

\section{6) Foam Agent}

Foam agent was organic composite. Its density was 1004 $\mathrm{kg} / \mathrm{m}^{3}$, and the dilution ratio to water was $1: 15$ by weight.

\section{B. Mix Proportion}

The volume method was adopted for the mix proportion design in this study. The water content in the matrix and the amount of foam added along with the ceramsite volume proportion were constant for CCC with different densities according to the principle of a single variable. For the experiment on the correlation, the apparent volume of ceramsite and the water-binder ratio were fixed at 0.40 and 0.28 , respectively. Class-II FA replacement for partial cement was $30 \%$ by weight. The superplasticizer was used with a basic dosage of $0.25 \%$ by weight of cementitious materials (cement and FA), but the dosage was not always constant, and the final consumption depended upon the workability of the fresh concrete. The remaining volume excluding the volume occupied by the aggregate and the matrix was the design volume of foam. In addition, taking the phenomenon of bubble loss in the process of mixing into account, the amount of actual foam volume added was $1.1-1.2$ times of the design content which ensured the fresh density was equal to or approximate to the design density. The details are shown in Table II.

TABLE II. MIX PROPORTIONS.

\begin{tabular}{|c|c|c|c|c|c|c|}
\hline $\begin{array}{l}\text { Design } \\
\text { density } \\
\left(\mathbf{k g} / \mathbf{m}^{3}\right)\end{array}$ & 600 & 700 & 800 & 900 & 1000 & 1100 \\
\hline Cement (kg) & 218.8 & 273.4 & 328.1 & 382.8 & 437.5 & 492.2 \\
\hline FA (kg) & 93.8 & 117.2 & 140.6 & 164.1 & 187.5 & 210.9 \\
\hline $\begin{array}{c}\text { Ceramsite } \\
\text { volume }\left(\mathrm{m}^{3}\right)\end{array}$ & 0.40 & 0.40 & 0.40 & 0.40 & 0.40 & 0.40 \\
\hline $\begin{array}{c}\text { Foam } \\
\text { volume }\left(\mathrm{m}^{3}\right)\end{array}$ & 0.46 & 0.40 & 0.34 & 0.29 & 0.23 & 0.17 \\
\hline Water (kg) & 87.5 & 109.4 & 131.3 & 153.1 & 175.0 & 196.9 \\
\hline $\begin{array}{l}\text { Superplastici } \\
\text { zer (kg) }\end{array}$ & 0.906 & 1.094 & 1.312 & 1.422 & 1.563 & 1.617 \\
\hline
\end{tabular}

To consider the influence of ceramsite volume proportion on $\mathrm{CCC}$, compressive strength test, and thermal conductivity test were carried out upon the specimens with the design density of $600 \mathrm{~kg} / \mathrm{m}^{3}$ (DD-600) under different ceramsite volume proportions. Ceramsite volume proportions were divided into seven grades ranging from 0.25 to $0.55 \mathrm{~m}^{3}$, and Table III lists the mix proportions.
TABLE III. MiX PROPORTIONS OF DD-600.

\begin{tabular}{|c|c|c|c|c|c|c|c|}
\hline $\begin{array}{c}\text { Design } \\
\text { density } \\
\text { (kg/m }\end{array}$ & \multicolumn{5}{|c|}{600} \\
\hline $\begin{array}{c}\text { Cement } \\
\text { (kg) }\end{array}$ & 259.8 & 246.1 & 232.4 & 218.8 & 205.1 & 191.4 & 177.7 \\
\hline FA (kg) & 111.3 & 105.5 & 99.6 & 93.8 & 87.9 & 82 & 76.2 \\
\hline $\begin{array}{c}\text { Ceramsite } \\
\text { volume } \\
\text { (m) }\end{array}$ & 0.25 & 0.30 & 0.35 & 0.40 & 0.45 & 0.50 & 0.55 \\
\hline $\begin{array}{c}\text { Foam } \\
\text { volume } \\
\text { (m) }\end{array}$ & 0.51 & 0.47 & 0.44 & 0.40 & 0.36 & 0.32 & 0.29 \\
\hline $\begin{array}{c}\text { Water } \\
\text { (kg) }\end{array}$ & 103.9 & 98.4 & 93.0 & 87.5 & 82.0 & 76.6 & 71.1 \\
\hline $\begin{array}{c}\text { Superplas } \\
\text { ticizer } \\
\text { (kg) }\end{array}$ & 1.076 & 0.949 & 1.062 & 0.906 & 0.850 & 0.820 & 0.711 \\
\hline
\end{tabular}

\section{Specimen Preparation}

The samples with the design density ranging from 600 to $1100 \mathrm{~kg} / \mathrm{m}^{3}$ were prepared, and then subjected to moist curing under the specified temperature. Each group of samples included three identical specimens and the average value measured was the final result. For the compressive strength test, $100 \mathrm{~mm}$ cubes prepared were measured at the age of 28 days. For the experiment of thermal properties, two groups of samples of $300 \times 300 \times 40 \mathrm{~mm}$ prisms were prepared, of which one group was used for thermal conductivity test and thermal storage coefficient test, and the other was used for balance control of thermal storage.

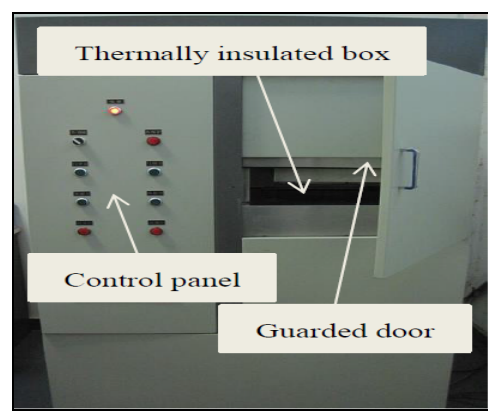

Fig. 2. DR-FD120A

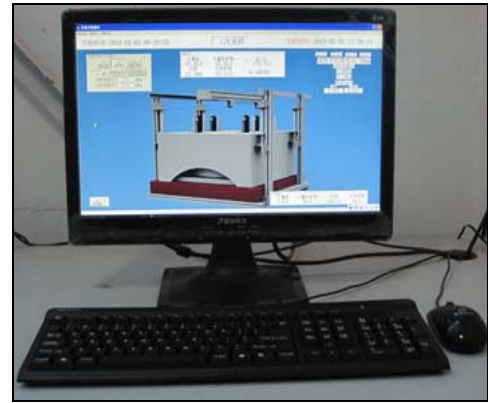

Fig. 3. Control program interface. 


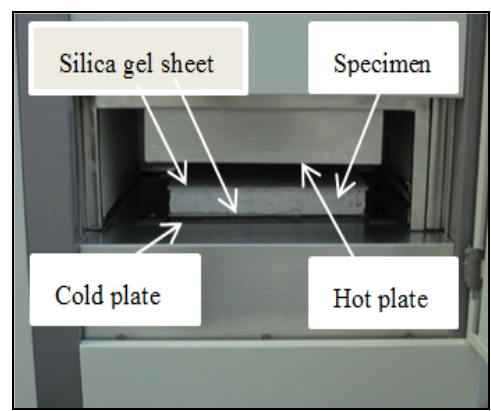

Fig. 4. The specimen sandwiched between the hot and cold plates.

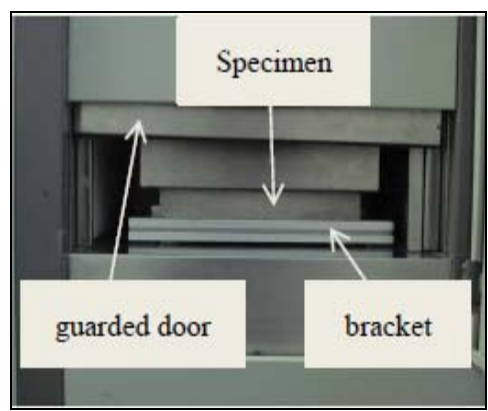

Fig. 5. The specimen placed on the bracket.

\section{Experimental Methods}

DR-FD120A, a type of apparatus for thermal property test, is shown in Fig. 2, and its control program interface is shown in Fig. 3.

The hot guarded plate method was used for the measurement of thermal conductivity. The specimen sandwiched between the hot and cold plates (Fig. 4) was sealed in a thermally insulated box. The thickness of the specimen was measured by the probes fixed to the hot plate. Temperature setting played a key role in the thermal insulation test. The cold plate temperature represented the room temperature, and hence, it was set at $18{ }^{\circ} \mathrm{C}$. Similarly, the hot plate temperature was kept at $38{ }^{\circ} \mathrm{C}$ to simulate the exterior temperature. Meanwhile, ambient temperature required for the test was $23 \pm 2{ }^{\circ} \mathrm{C} .1 \mathrm{~mm}$ silica gel sheets with a size of $300 \times 300 \mathrm{~mm}$ were stuffed between the specimen surface and the plates for the complete compaction of the contact surface, and it was less than $1 \%$ at most that repeatability error of the results measured in this way.

The calculation of thermal conductivity of CCC conforms to Fourier's law of one dimensional heat conduction, as follows:

$$
\mathrm{q}=-\mathrm{k} \frac{\mathrm{dT}}{\mathrm{dx}}
$$

where, $\mathrm{q}$ is heated flux, $\mathrm{W} / \mathrm{m}^{2} ; \mathrm{k}$ is thermal conductivity or thermophysical property, $\mathrm{W} / \mathrm{m} \mathrm{K}$; $\mathrm{dT}$ is the temperature gradient from hot to the cold surface, ${ }^{\circ} \mathrm{C}$; $\mathrm{dx}$ is the distance between the hot and cold surfaces, $\mathrm{m}$. The negative value indicates that heat transfers from the hot surface to the cold surface.

The environmental balance control method was used for the measurement of the thermal storage coefficient. The specimen along with the bracket (Fig. 5) was sandwiched between the hot and cold plates. The hot plate temperature was set at $38^{\circ} \mathrm{C}$, and the cold plate temperature was consistent with ambient temperature. Automatically thermal storage balance control of the specimen was performed by inputting density, thickness and thermal conductivity on the control program interface. The specimen along with the bracket was taken out after the end of balance control, and then the thermal storage coefficient was tested over the specimen conducted for thermal conductivity test according to the method for thermal conductivity determination [5].

The calculation of thermal storage coefficient (S) of CCC is based on Chinese industry standard JGJ 51-2002 (Technical specification for lightweight aggregate concrete), as follows:

$$
\mathrm{S}=0.51 \cdot(\mathrm{k} \cdot \mathrm{C} \cdot \rho)^{\frac{1}{2}}
$$

where, $\mathrm{S}$ is thermal storage coefficient, $\mathrm{W} /\left(\mathrm{m}^{2} \mathrm{~K}\right) ; \mathrm{k}$ is thermal conductivity or thermophysical property, $\mathrm{W} / \mathrm{m} \mathrm{K} ; \mathrm{C}$ is specific heat capacity, $\mathrm{J} /(\mathrm{kg} \mathrm{K}) ; \rho$ is density, $\mathrm{kg} / \mathrm{m}^{3}$.

\section{RESULTS AND DISCUSSION}

\section{A. The fluidity of CCC}

In this study, a large number of experiments indicated that the fresh concrete showed good workability with the slump flow in the range of 400-700 $\mathrm{mm}$.

The slump flow of the concrete with variations of the dosage of the superplasticiser is shown in Fig. 6. It can be seen that the slump flow is dramatically increasing as the dosage of the superplasticiser changes from $0.25 \%$ to $0.3 \%$, and then it tends to be constant regardless of the variations of the densities. The concrete with higher density shows a higher increment in slump flow as the dosage increases, and while the critical dosage drops, at which the concrete begins to exhibit good workability. This can be attributed to self-weight of the concrete.

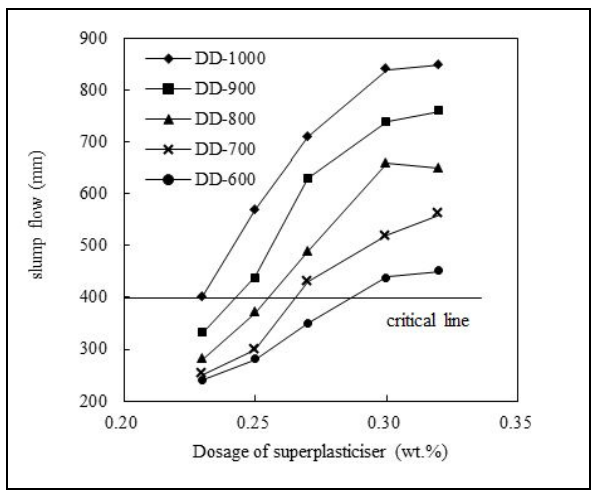

Fig. 6. The fluidity of CCC. 


\section{B. Relationship between Thermal Conductivity and Density}

The design densities of CCC were 600, 700, 800, 900, 1000 and $1100 \mathrm{~kg} / \mathrm{m}^{3}$, and the fresh densities and dry densities are shown in Fig. 7. It can be seen that the fresh density is within $\pm 50 \mathrm{~kg} / \mathrm{m}^{3}$ of the design density for all the specimens. The dry density was approximately $100 \mathrm{~kg} / \mathrm{m}^{3}$ lower as compared to its fresh density. The variation between the design density and the fresh density was attributed to a number of factors including continued expansion and mergence of the foam after its discharge, and loss of foam during mixing.

There have been some reports about the correlation between thermal conductivity and density so far. It was found that the insulation was in approximately inverse proportion to the density of concrete [6]. Blanco et al. proposed an exponential pattern on the lightweight concrete manufactured with cenospheres [7].

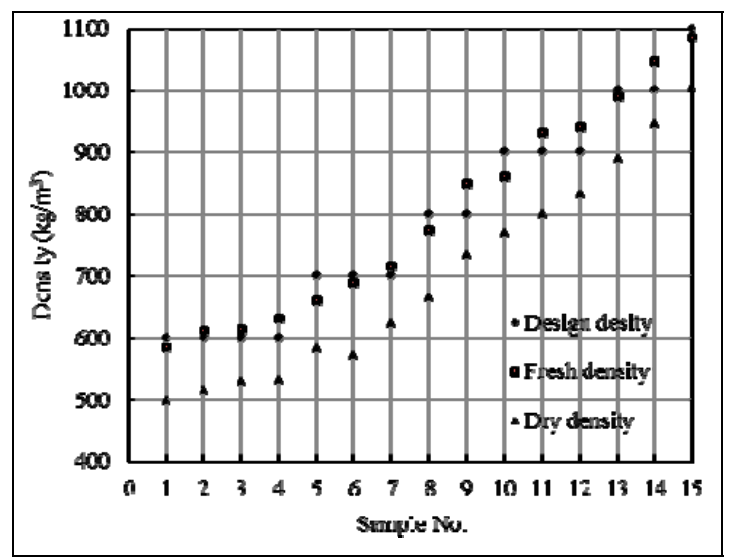

Fig. 7. Density category of CCC.

It can be seen that the increase of the dry density leads to higher thermal conductivity, as shown in Fig. 8. This is attributed to the reduction of the total voids filled with air, whose thermal conductivity is inferior to that of the matrix, therefore accounting for the effect of the dry density on the thermal conductivity.

Among all the specimens, the lowest thermal conductivity $(0.137 \mathrm{~W} / \mathrm{m} \mathrm{K})$ was obtained from the specimen (DD-600) with the dry density of $498 \mathrm{~kg} / \mathrm{m}^{3}$. The relationship between thermal conductivity and dry density $\left(\rho_{\mathrm{d}}\right)$ conformed to a polynomial pattern. The equation to predict the thermal conductivity of $\mathrm{CCC}$ was given as follows:

$$
\mathrm{k}=2 \times 10^{-7} \rho_{\mathrm{d}}^{2}+6 \times 10^{-5} \rho_{\mathrm{d}}+0.0698\left(\mathrm{R}^{2}=0.986\right)
$$

The coefficient of determination (0.986) shows a fairly good prediction for thermal conductivity. Meanwhile, it also can be concluded that density is a primary characteristic for thermal conductivity.

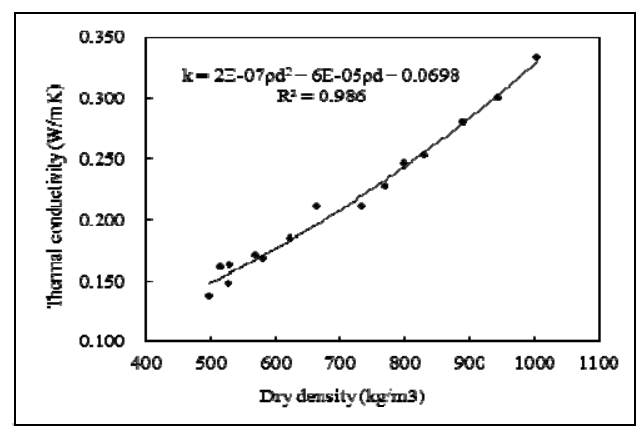

Fig. 8. Variation of thermal conductivity with dry density.

\section{Relationship between Thermal Conductivity and Compressive Strength}

Thermal conductivity and compressive strength of the specimens with different densities are shown in Fig. 9. It can be seen that there is a growing tendency in the thermal conductivity with the increase in compressive strength $\left(f_{c u}\right)$, and the following equation was obtained to establish relations by polynomial regression.

$$
\mathrm{k}=0.0049 \mathrm{f}_{\mathrm{cu}}^{2}-0.0206 \mathrm{f}_{\mathrm{cu}}+0.1763\left(\mathrm{R}^{2}=0.918\right)
$$

The relevance between these two variables can be indirectly attributed to the density. The specimen with low density has high air content inside due to a higher quantity of foam, thus reducing the rate of heat transfer through the specimen. Meanwhile, larger air-voids and wide distribution of air-void sizes in the specimen with low density bring about the reduction in strength. But the air-void distribution at high densities has no effect on compressive strength, probably because of attaining more uniform distribution of voids at low foam volume ranges or higher density ranges [8]. This also can be validated from the observations made by Visagie and Kearsley [9]. In addition, when the density increases to a certain value, the ceramsite becomes the weak section of the specimen due to lower cylinder compressive strength (1.3 $\mathrm{MPa}$ ), and this eventually leads to lower variation in compressive strength under higher densities. Therefore, both the air-void distribution and the ceramsite are fundamental factors accounting for relatively low correlation.

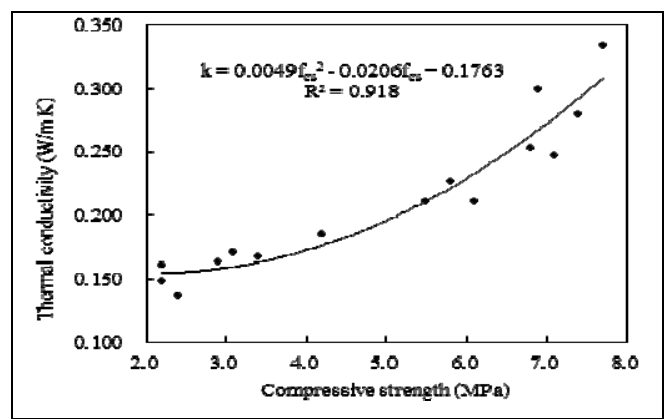

Fig. 9. Variation of thermal conductivity with compressive strength. 


\section{Relationship between Thermal Conductivity and Thermal Storage Coefficient}

Heat transfer process of the building envelop is very complicated. There are many influencing factors including temperature difference between inside and outside, surface heat transfer coefficient, structural thermal resistance and the circulation of heat storage and heat release in the heat transfer process [10]. As a thermal index of building envelop, thermal storage coefficient demonstrates the ability to resist the temperature wave. In addition, thermal storage coefficient is also a basic parameter for the determination of the thermal stability.

To clarify the correlation between thermal conductivity and thermal storage coefficient, the two key thermal indexes for CCC, the specimens with different densities were tested, and the thermal storage coefficient was plotted as a function of the thermal conductivity, and the thermal storage coefficientthermal conductivity regression curve obtained is shown in Fig. 10 . An equation on the correlation between the thermal storage coefficient and thermal conductivity was obtained as follows:

$$
\mathrm{S}=13.976 \mathrm{k}+0.3084\left(\mathrm{R}^{2}=0.958\right)
$$

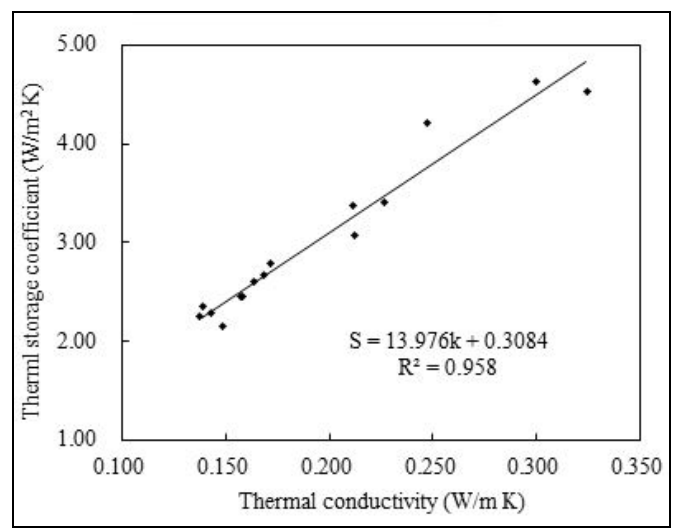

Fig. 10. Variation of thermal storage coefficient with thermal conductivity

The coefficient of determination (0.989) indicates thermal storage coefficient is closely proportional to the thermal conductivity. The thermal conductivity is almost within $0.1-$ $0.3 \mathrm{~W} / \mathrm{m} \mathrm{K}$ for the specimens with different densities, and so thermal storage coefficient is approximately 15 times of the thermal conductivity for CCC.

\section{E. The Influence of Ceramsite Volume Proportion on CCC}

In this study, clay ceramsite was used as the coarse aggregate, and the porosity measured in the ceramsite was $74 \%$, which gave itself heat insulation ability and lower cylinder compressive strength. Therefore, on the one hand, the addition of the ceramsite improved the thermal insulation of CCC, but on the other hand, the difference in the content of the ceramsite had a significant effect on the compressive strength. Giving comprehensive consideration to thermal insulation and compressive strength, there is an appropriate proportion of the ceramsite for CCC with different densities. This paper only discussed CCC with the design density of $600 \mathrm{~kg} / \mathrm{m}^{3}$, as shown in Fig. 11.

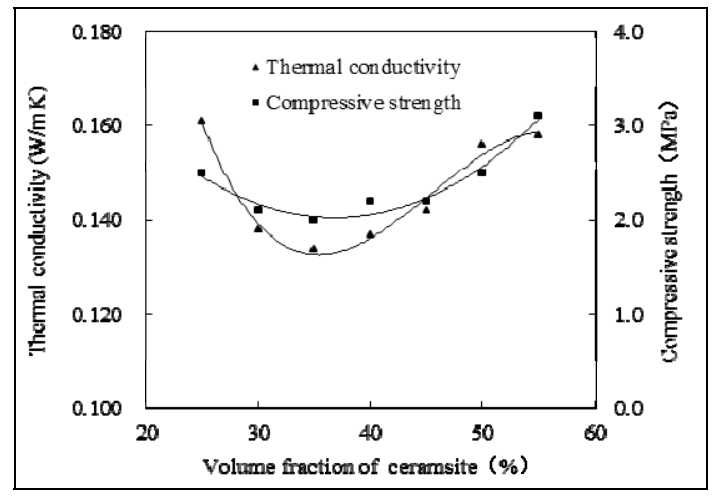

Fig. 11. DD-600

Cubic polynomial fitting curves connecting thermal conductivity and compressive strength with volume proportion of ceramsite are shown in Fig. 11. It can be seen that both thermal conductivity and compressive strength decrease with the increment of volume proportion of ceramsite and then increase. In addition, when the volume proportion of ceramsite is $35 \%$, both reach the critical value, $0.135 \mathrm{~W} / \mathrm{m} \mathrm{K}$ and 2.0 $\mathrm{MPa}$, respectively. Out of forming process and workability, the volume proportion should be less than $55 \%$. On the other hand, the ceramsite contributes to resisting shrinkage as well as improving strength for CCC with low density, and so the volume proportion should be more than $20 \%$. Considering these factors and referring to Fig.11, it can be concluded that the appropriate volume proportion of ceramsite is $45 \%$.

In this study, random sampling was conducted on the autoclaved aerated concrete and CCC used in the actual project, and the samples were tested in the lab. The dry densities both were $600 \mathrm{~kg} / \mathrm{m}^{3}$, compressive strength of CCC was about 4.6 $\mathrm{MPa}$ compared to 3.0 MPa for that of autoclaved aerated concrete, thermal conductivity of CCC was $0.156 \mathrm{~W} / \mathrm{m} \mathrm{K}$ compared to $0.162 \mathrm{~W} / \mathrm{m} \mathrm{K}$ for that of autoclaved aerated concrete, saturated water absorption of CCC was $38.4 \%$ compared to $69.5 \%$ for that of autoclaved aerated concrete. As self-insulation wall materials, CCC exhibits higher strength, better thermal insulation, and lower water absorption compared to autoclaved aerated concrete. In addition, CCC showed better thermal stability compared to autoclaved aerated concrete and concrete hollow block $[5,10]$.

\section{CONCLUSIONS}

According to the experimental results of ceramsite cellular concrete (CCC) specimens, the following conclusions can be drawn.

1) For the specimens with different densities, the fresh concrete shows good workability with the slump flow in the range of $400-700 \mathrm{~mm}$. Fresh density is within $\pm 50 \mathrm{~kg} / \mathrm{m}^{3}$ of the design density, and dry density is approximately $100 \mathrm{~kg} / \mathrm{m}^{3}$ lower as compared to the fresh density. 
2) The thermal conductivity increases with dry density and compressive strength. The lowest thermal conductivity of $0.137 \mathrm{~W} / \mathrm{m} \mathrm{K}$ is obtained from the specimen (DD-600) with the dry density of $498 \mathrm{~kg} / \mathrm{m}^{3}$.

3) A polynomial prediction model equation is derived to accurately estimate the thermal conductivity with dry density or compressive strength. Furthermore, there is a good linear dependence of thermal storage coefficient on the thermal conductivity, and the thermal storage coefficient is approximately 15 times of thermal conductivity for CCC.

4) There is an appropriate volume proportion of ceramsite influencing thermal conductivity and compressive strength for CCC with different densities, and the appropriate volume proportion is $45 \%$ for CCC with the design density of 600 $\mathrm{kg} / \mathrm{m}^{3}$.

\section{REFERENCES}

[1] R.C. Valor, "Cellular concretes part 1 composition and methods of preparation” ACI. J., vol. 50, pp. 773-96, 1954

[2] M.R. Jones and A. McCarthy, "Behavior and assessment of foamed concrete for construction applications" In: R.K. Dhir, M.D. Newlands, A McCarthy, editors. Use of foamed concrete in construction. London: Thomas Telford, pp. 61-88, 2005

[3] K. Ramamurthy, E.K. Kunhanandan Nambiar and G. Indu Siva Ranjani, "A classification of studies on properties of foam concrete" Cem. Concr. Comp., vol. 31, pp. 388 - 96, 2009

[4] M.S. Goual, A. Bali and M. Queneudec, "Effective thermal conductivity of clayey aerated concrete in the dry state: experimental results and modelling” J. Phys. D.: Appl. Phys., vol. 32(23), pp. 3041 - 46, 1999

[5] Q. Wang, Y. Shi, and T. Qu, et al. "A testing and analysis on thermal performance of ceramsite cellular concrete block wall" New. Build. Mater., vol. 41(12), pp. 26-30 (In Chinese), 2014

[6] Shrivastava. "Lightweight aerated concrete -a review" Indian. Concr. J., vol. 51, pp. $10-23,1977$

[7] B.P. Garcir, P. Mateos, and J. Ayala. "Characteristics and properties of lightweight concrete manufactured with cenospheres" Cem. Concr. Res., vol. 30 , pp. $1715-22,2000$

[8] H.K. Kim, J.H. Jeon, and H.K. Lee. "Workability, and mechanical, acoustic and thermal properties of lightweight aggregate concrete with a high volume of entrained air" Constr. Build. Mater., vol. 29, pp. 193 20, 2012

[9] M. Visagie, and E.P. Kearsely. "Properties of foamed concrete as influenced by air-void parameters" Concrete/Beton.,vol. 101, pp. $8-14$, 2002

[10] Q. Wang, X. Shi, and T. Qu, et al. "Study on heat transfer performance of self-insulation block walls in hot summer and cold winter area" Constr. Technol. vol. 43(24), pp. 19-23 (In Chinese), 2014 